\title{
BCIG-SMAC medium and PMA-qPCR for differential detection of viable Escherichia coli in potable water
}

\author{
Rehan Deshmukh ${ }^{1,2}$, Sunil Bhand ${ }^{3}$, Utpal Roy $^{1 *}$ \\ ${ }^{1}$ Department of Biological Sciences, Birla Institute of Technology and Sciences, Pilani, Goa, India \\ ${ }^{2}$ Department of Biology, Faculty of Science, Dr. Vishwanath Karad MIT World Peace University, Pune, India \\ ${ }^{3}$ Department of Chemistry, Birla Institute of Technology and Sciences, Pilani, Biosensor Laboratory, Goa, \\ India
}

Received: February 2021, Accepted: August 2021

\begin{abstract}
Background and Objectives: Public health protection requires timely evaluation of pathogens in potable water to minimize outbreaks caused by microbial contaminations. The present study was aimed at assessing the microbiological quality of water obtained from Shantinagar (a rural area in the South Goa region of Goa, India) using 5-Bromo-4-Chloro-3-Indoxyl $\beta$-D-glucuronide-Sorbitol MacConkey agar (BCIG-SMAC) medium and, propidium monoazide-quantitative polymerase chain reaction (PMA-qPCR) assay for differential detection and quantification of viable Escherichia coli cells in water samples.

Materials and Methods: Membrane filtration method was used for both BCIG-SMAC medium and PMA-qPCR methods. To determine the efficiency of detection of viable cells, we first evaluated the PMA treatment protocol and established the standard calibration curves using previously reported primers.

Results: PMA-qPCR detected as low as 7 femtograms of DNA of E. coli per qPCR reaction whereas the limit of detection (LOD) of BCIG-SMAC medium was $1.8 \mathrm{CFU} / 100 \mathrm{~mL}$. A total of 71 water samples spanning 2017-2018 have been analyzed using BCIG-SMAC medium and PMA-qPCR, of which $95.77 \%$ (68/71) and 7.04\% (5/71) were found to be total E. coli and E. coli $\mathrm{O} 157: \mathrm{H} 7$, respectively. PMA-qPCR study showed the viable counts of total viable $E$. coli cells ranging from 3 $\mathrm{CFU} / 100 \mathrm{~mL}$ to $8.2 \times 10^{2} \mathrm{CFU} / 100 \mathrm{~mL}$. The total $E$. coli CFU/100mL quantified by PMA-qPCR significantly exceeded (paired t-test; $P<0.05)$ the number on BCIG-SMAC medium.

Conclusion: The present study indicates that the microbiological quality of environmental water samples analyzed do not comply with the regulatory standard. Therefore, special attention is warranted to improve the overall portable quality of water in the perspective of public health.
\end{abstract}

Keywords: Coliforms; Detection; Escherichia coli; Pathogens; Propidium monoazide; Public health

\section{INTRODUCTION}

Water must be free from pathogens to become reliable for drinking purpose. Public health protection necessitates immediate evaluation of microorganisms in drinking water to prevent outbreaks of microbial contamination. Because of the poor sanitation, approximately one billion people depend on contaminated water sources which amounts to 2.2 million annual deaths caused mainly because of diarrheal diseases which is around $4 \%$ of the global disease burden. Children under the age of five are

\footnotetext{
*Corresponding author: Utpal Roy, Ph.D, Department of Biological Sciences, Birla Institute of Technology and Sciences, Pilani, Goa, India. Tel: +91-8322580393_Email: utpalroy@gmail.com
} 
more vulnerable to diarrheal diseases which account for more than $90 \%$ of annual deaths with about 4000 children die per day (UNICEF, 2015) (1). Escherichia coli is widely recognized not only as the indicator of faecal contamination of water resources but also a pathogen (2). In India, cases of acute gastroenteritis caused by drinking of contaminated water have been estimated to be 10.87 million every year. Most of the outbreaks occurred from bacterial and viral pathogens, for example E. coli, Salmonella spp., Shigella spp., and hepatitis viruses A and B $(2,3)$.

Water quality for potable purposes has been evaluated based on microbiological media and further detection using culture-independent methods. However, culture-based methods and biochemical assays take up to 18-96 hours for isolation and identification of $E$. coli strains which makes use of selective media or chromogenic agar to detect pathogens such as E. coli $\mathrm{O} 157: \mathrm{H7}$ (4) while giving little information about the type of the strain or the isolate. In order to effectively monitor future outbreaks, it is necessary to have availability of rapid yet specific methods for detection of E. coli cells. The quantitative PCR (qPCR) is one such method for detection of microbial pathogens mainly in terms of selectivity, specificity and rapidity $(5,6)$. While the q-PCR alone cannot differentiate between the viable and non-viable bacterial cells in water as DNA extracted from dead cells can also serve as a template for PCR amplification as efficiently as the DNA obtained from viable cells. Persistence of DNA from dead or membrane compromised cells and lack of distinction of viability in qPCR amplification could cause false- positive results, hence, lead to overestimation of the viable cell counts in water sample (7-9). Such limitation restricts the effective use of qPCR for accurate microbiological examination of water sample.

Nocker et al. (10) reported Propidium monoazide (PMA) based novel method which selectively inhibits the PCR amplification of DNA derived from dead or membrane compromised cells by treating samples with PMA before DNA extraction (10). PMA can penetrate membrane compromised cells by intercalating the DNA when exposed to an intense light source leading to covalent bond formation between PMA and the two DNA strands. Of note, PMA cannot penetrate viable cells with intact membranes, thus, only DNA from viable cells can be amplified by PCR followed by PMA treatment of dead and viable cell mixture. This method has been successfully used for microbiological monitoring of pathogens in a number of recent studies (11-15).

Shantinagar is a rural settlement in Vasco-DaGama, South Goa, India. The residents obtain water of unknown quality from various sources such as wells and rainwater. However, these water bodies hardly undergo proper treatment that could assure its compliance for human consumption. Therefore in the present study, we report the microbiological assessment of water quality of Shantinagar area using 5-Bromo-4-Chloro-3-Indoxyl $\beta$-D-glucuronide-Sorbitol MacConkey agar (BCIG-SMAC) medium and PMA-qPCR assay for differential detection and quantification of $E$. coli cells in water samples. This study has been important in order to determine not only the water quality but also to implement plausible measures for supply of safe water to the area.

\section{MATERIALS AND METHODS}

Bacterial strains and culture conditions. The E. coli MTCC 3221 and E. coli ATCC 43895 were procured from Microbial Type Culture Collection and Gene Bank (MTCC), India and American Type Culture Collection (ATCC), US. E. coli strains were grown to logarithmic phase (Optical Density at 600 $\mathrm{nm}\left[\mathrm{OD}_{600}\right], 0.5$ to 0.6 ) in Luria-Bertani (LB) broth medium at $37^{\circ} \mathrm{C}$.

BCIG-SMAC medium. In the present study, the agar medium most commonly used for the differential identification of $E$. coli strains was BCIG-SMAC agar medium. All the individual media components were procured from HiMedia (Mumbai, India). The composition of the medium per litre is as follows: Peptic digest of animal tissue 17g; Proteose peptone $5 \mathrm{~g}$; Sorbitol 10g; Sodium chloride 7.5g; Sodium dodecyl sulphate (SDS) 0.2g; Sodium taurocholate $1.5 \mathrm{~g}$; BCIG 30 mg; Neutral red 30 mg; agar 18g. The $\mathrm{pH}$ of the medium was maintained at $7.2 \pm 0.2$. Five milliliter of freshly prepared filter-sterilized solution of cefsulodin $(1 \mathrm{mg} / \mathrm{mL})$ was added to the tempered agar medium.

Collection of water samples. Shantinagar is located in South Goa district of Goa between the coordinates $15^{\circ} 23^{\prime} 24.1^{\prime \prime}$ north and $73^{\circ} 49^{\prime} 39.6^{\prime \prime}$ east. The area is usually characterized by rainy season (June to September), winter season (November to February) 
and summer (March to May). Water samples were collected from a well and four different households during two sampling periods $(n=71)$ from the months June to September each in 2017 and 2018. The well was selected primarily because its water was mainly used for potable purpose and large number residents received the water supply (Supplementary Table S1). The water samples were collected in sterile screw capped bottles to avoid contamination and stored at $4^{\circ} \mathrm{C}$ and processed within 1-2 days as mentioned below. The water quality testing was performed in accordance with the international standards as outlined by US environmental protection agency (USEPA, 2002). E. coli counts were confirmed by filtering 100 $\mathrm{mL}$ of water sample through sterile polyethersulfone (PES) membrane filter (47-mm diameter, $0.45 \mu \mathrm{m}$ pore size; Axiva Biotech, India) on a 3-place standard manifold (Axiva Sichem Biotech, India). The filter was then incubated on BCIG-SMAC agar supplemented with $5 \mu \mathrm{g} / \mathrm{mL}$ cefsulodin (MP Biomedicals, Santa Ana, USA) for $24 \pm 2 \mathrm{~h}$ at $37^{\circ} \mathrm{C}$.

Membrane filtration and spiking of water samples. E. coli O157:H7 ATCC 43895 and E. coli MTCC 3221 were employed as standard strains for spiking experiments. Each strain was grown to logarithmic phase (Optical Density at $600 \mathrm{~nm}\left[\mathrm{OD}_{600}\right], 0.5$ to 0.6 ) with constant shaking in $100 \mathrm{~mL} \mathrm{LB}$ broth at $37^{\circ} \mathrm{C}$. Post-incubation, four aliquots comprising $400 \mu \mathrm{L}$ each of E. coli O157:H7 ATCC 43895 and E. coli MTCC 3221 were spiked into autoclaved environmental water samples and filtered through sterile PES membrane filters (16). The filter was then incubated on BCIG- SMAC agar at $37^{\circ} \mathrm{C}$ for determination of bacterial growth and colour. The membrane filtration method was used for both BCIG-SMAC agar and PMA-qPCR method (5). Sterility controls for membrane filters and bacteriological saline used for rinsing the filtration apparatus were also standardized.

Killing conditions and PMA treatment. PMA treatment has been described previously (16). PMA (Biotium Inc., Hayward, CA) was dissolved in $20 \%$ dimethyl sulfoxide (DMSO; Waltham, US) to obtain a stock concentration of $10 \mathrm{mM}$ and stored at $-20^{\circ} \mathrm{C}$ in dark. In the current study, PMA treatment was optimized for high throughput screening of E. coli strains as discussed below. Aliquots of $1 \mathrm{~mL}$ of $0.5 \mathrm{OD}_{600}(4$ $\times 10^{8} / \mathrm{mL}$ ) viable cells each of $E$. coli $\mathrm{O} 157: \mathrm{H} 7$ and $E$. coli MTCC 3221 were added into $1.5 \mathrm{~mL}$ non-trans- parent (opaque) eppendorf tubes separately and centrifuged at 5000 rotations per minute (rpm) for $5 \mathrm{~min}$ to remove the media components. The pellet was washed twice with sterile saline buffer to obtain final bacterial suspension of $400 \mu \mathrm{L}$. The bacterial cells were killed by using boiling water bath for 2-2.5 min. The killed bacterial cells were subsequently kept at $-20^{\circ} \mathrm{C}$ for $3-5$ mins. An aliquot of $2.0 \mu \mathrm{L}$ of $10 \mathrm{mM}$ PMA was added to each $400 \mu \mathrm{L}$ of viable cells, heatkilled cells, and appropriate mixtures of viable and dead cells to obtain a final concentration of $50 \mu \mathrm{M}$. The PMA-treated bacterial suspensions were incubated at room temperature in the dark for 10 mins with gentle shaking three to four times for $3 \mathrm{~s}$ each time. Following the incubation, bacterial suspension was exposed to a 600 Watt (W) halogen light (Philips, India) for $10 \mathrm{~min}$ at a distance of $20 \mathrm{~cm}$ from the light source. Loss of viability of heat killed bacterial cells was tested by spreading $100 \mu \mathrm{l}$ of cell suspension on the LB agar plates which yielded less than $2 \mathrm{CFU}$ after incubation at $37^{\circ} \mathrm{C}$ for $24 \mathrm{~h}$.

DNA extraction and PMA-qPCR. DNA from $E$. coli O157:H7 ATCC 43895 and E. coli MTCC 3221 cells and nucleic acid from environmental water samples were extracted using a FastDNA ${ }^{\mathrm{TM}}$ Spin Kit (MP Biomedicals, Santa Ana, USA) according to the manufacturer's instructions. Concentrations of DNA were determined by using NanoDrop ${ }^{\mathrm{TM}}$ spectrophotometer (Thermo scientific). The purified DNA suspension was stored at $-20^{\circ} \mathrm{C}$ until PMA-qPCR amplification. For PMA-qPCR, the following primer sets were used: z3276-Forward (F), 5'- GCACTAAAAGCTTGGAGCAGTTC; and z3276-Reverse (R), 5'-AACAATGGGTCAGCGGTAAGGCTA (17) targeting the open reading frame marker (ORF) of E. coli $\mathrm{O} 157: \mathrm{H} 7$ and IEC-UP 5'-CAA TTTTCGTGTCCCCTTCG and IEC-DN 5'-GTTAATGATAGTGTGTCGAAAC (18) targeting distal and proximal conserved flanking regions of the 16S rRNA gene, the Internal Transcribed Spacer (ITS) region and the 23S rRNA gene for detection of total strains of $E$. coli to amplify to an expected size of $178 \mathrm{bp}$ and $450 \mathrm{bp}$ fragments respectively. Primers targeting the z3276 genetic marker have been shown to be highly specific for detection of E. coli $\mathrm{O} 157: \mathrm{H7}$ (17) whereas IES primers are specific towards detection of total E. coli (18). A process control consisting of 500 Bacillus atrophaeus spores was incorporated in the qPCR reaction. The spores were prepared according to Picard et al. (19). Primer se- 
quence, F-5'-CACTTCATTTAGGCGACGATACT-3' and R-5'-TTGTCTGTGAATCGGATCTTTCTC-3', was used for detection of spores in qPCR reactions (19). The oligonucleotide primers were synthesized by Integrated DNA Technologies (Coralville, US). The amplification reaction was carried out by using FastStart Universal SYBR Green Master (Roche, Switzerland). Five microliter of template was transferred directly to a $15-\mu \mathrm{L}$ PCR mixture containing 50 $\mathrm{pmol} / \mu \mathrm{L}$ each of forward and reverse primer, $3.3 \mu \mathrm{g} / \mu$ L BSA, $2 \times$ FastStart Universal SYBR Green Master and the volume was adjusted by PCR grade water (Roche, Switzerland). In each experiment, a volume of $5 \mu \mathrm{L}$ sterile water was added to PCR mixtures as a negative control. The qPCR mixtures were subjected to thermal cycling for 180 seconds at $95^{\circ} \mathrm{C}$ and then 40 cycles of 30 seconds at $95^{\circ} \mathrm{C}, 30$ seconds at $58^{\circ} \mathrm{C}$, and 30 seconds at $72^{\circ} \mathrm{C}$. The amplification reaction was performed using LightCycler® 96 Real-Time PCR system (Roche, Switzerland) in triplicates.

Sensitivity and Limit of Detection (LOD) of BCIG-SMAC and PMA-qPCR. The standard curve was generated using purified DNA extracted from pure cultures $(\mathrm{OD} 600=0.5)$ of the E. coli $\mathrm{O} 157: \mathrm{H} 7$ ATCC 43895 and E. coli MTCC 3221 in the range 56 picogram to 0.007 picogram and the experiments were performed in triplicate. The cycle of quantitation $(\mathrm{Cq})$ values for each set of reactions were plotted against DNA dilution to obtain a standard curve. The Limit of detection (LOD) was defined as the lowest concentration in standard curve at which $95 \%$ of the positive samples were detected by PMA-qPCR. The PMA-qPCR was then applied for differential detection and quantification of viable E. coli strains from environmental water samples. For determining the sensitivity of BCIG-SMAC, the water samples were spiked with known numbers of $E$. coli cells mainly in the range of $100,50,25,10,5$ and $1 \mathrm{CFU} / 100 \mathrm{~mL}$.

\section{RESULTS}

Effect of PMA treatment on viable cells and mixtures of viable and dead cells. Under optimized conditions, PMA-qPCR assay was used to differentiate viable cells from a mixture of viable and dead cells of E. coli O157:H7 ATCC 43895 (Fig. 1A) and E. coli MTCC 3221 (Fig. 1B) with all reactions performed in triplicates. PMA-qPCR showed that the $\mathrm{Cq}$ values of killed PMA-treated cells were higher than the $\mathrm{Cq}$ values of mixture of viable and dead cells for both $E$. coli $\mathrm{O} 157: \mathrm{H7}$ and E. coli MTCC 3221 as depicted in Fig. 1C. Thus, the descending trend in $\mathrm{Cq}$ values of DNA from mixture of viable and dead cells (mean Cq, 17.21 and 26.60 for E. coli $\mathrm{O} 157: \mathrm{H} 7$ and E. coli MTCC 3221 respectively) exclusively reflects the amount of DNA of viable cells (mean Cq, 17.87 and 27.78 for E. coli $\mathrm{O} 157: \mathrm{H} 7$ and E. coli MTCC 3221 respectively) in the mixture despite presence of large amount of dead cells, hence, indicating the complete inhibition of DNA amplification from dead cells after PMA treatment.

Sensitivity of BCIG-SMAC and PMA-qPCR. The sensitivity of the PMA-qPCR was determined by generating the standard curves (Fig. 2) for quantification using the optimized PMA-qPCR amplification assay conditions based on DNA dilutions ranging from 56 to $0.007 \mathrm{pg}$ for pathogenic E. coli $\mathrm{O} 157: \mathrm{H} 7$ and non-pathogenic E. coli MTCC 3221 strains. The analysis of the standard curve (Fig. 2) derived from the PMA-based RT-qPCR using DNA from E. coli strains (both E. coli O157:H7 and MTCC 3221) revealed that the LOD was approximately 7 femtogram, which is equivalent to approximately 1 cell of $E$. coli (5). However, the LOD of mSMAC was $1.8 \mathrm{CFU} / 100 \mathrm{~mL}$. The range of amplification efficiencies of the PMA-qPCR was $88-90 \%$ and $93-95 \%$ for E. coli O157:H7 ATCC 43895 and E. coli MTCC 3221, respectively.

\footnotetext{
Analysis of water samples using PMA-qPCR and BCIG-SMAC Culture Medium for differential detection and quantification of $\boldsymbol{E}$. coli cells. A total of 71 water samples from 2017 and 2018 have been analyzed using BCIG-SMAC medium and PMA-qPCR, out of which $95.77 \%(68 / 71)$ and $7.04 \%(5 / 71)$ were found to be total E. coli and E. coli $\mathrm{O} 157: \mathrm{H} 7$, respectively. Using PMA-qPCR, the viable counts of total E. coli viable cells ranged from $3 \mathrm{CFU} / 100 \mathrm{~mL}$ to $8.2 \times 10^{2} \mathrm{CFU} / 100 \mathrm{~mL}$ (Fig. 3). When the water samples were PMA-untreated, the $E$. coli cells were much higher in number approximately between $6 \mathrm{CFU} / 100$ $\mathrm{mL}$ to $1 \times 10^{3} \mathrm{CFU} / 100 \mathrm{~mL}$ indicating a large number of DNA from dead cells. On the BCIG-SMAC, the non-pathogenic E. coli ranged from $10 \mathrm{CFU} / 100$ $\mathrm{mL}$ to $120 \mathrm{CFU} / 100 \mathrm{~mL}$. Similarly, PMA-treated qPCR of viable $E$. coli $\mathrm{O} 157: \mathrm{H} 7$ cells ranged from 2 $\mathrm{CFU} / 100 \mathrm{~mL}$ to $10 \mathrm{CFU} / \mathrm{mL}$ whereas PMA-untreated qPCR revealed E. coli $\mathrm{O} 157: \mathrm{H} 7$ cells ranging from
} 

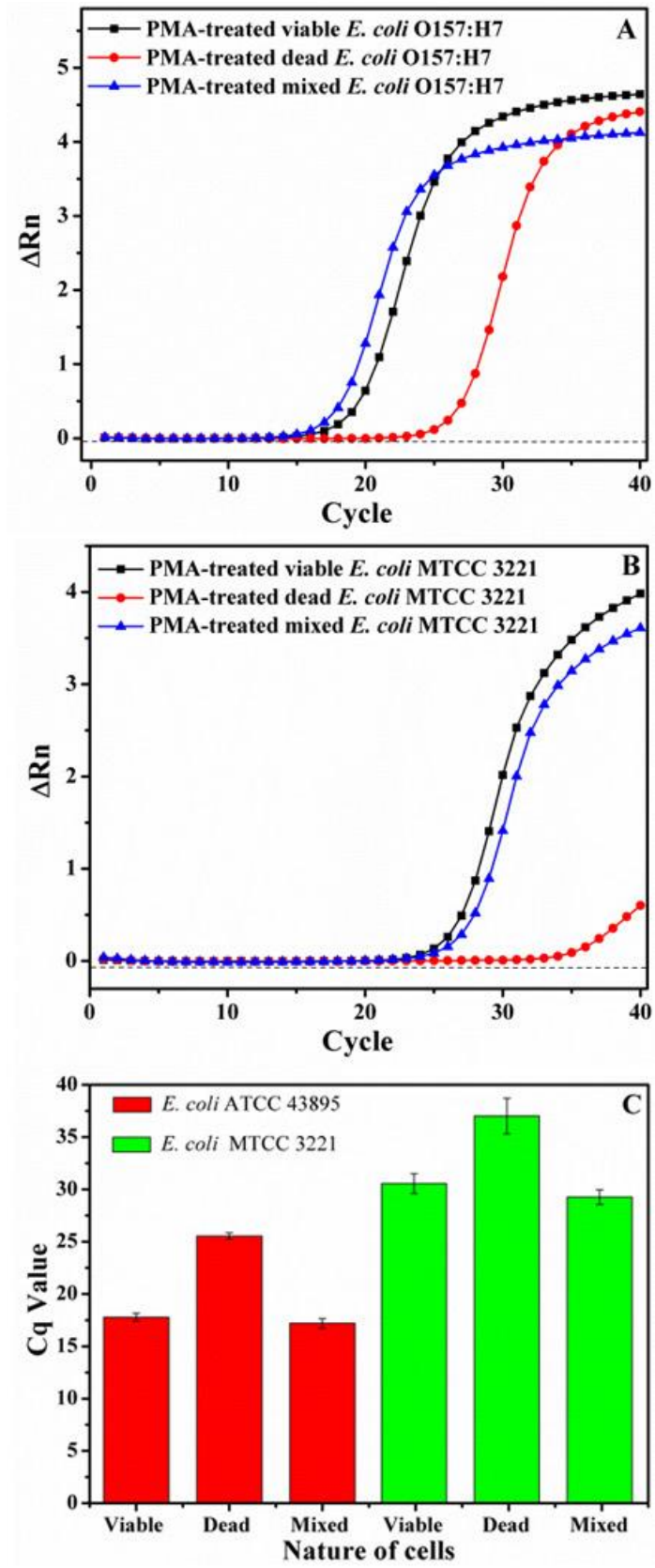

Fig. 1. Differentiation of viable cells in viable and dead cell mixtures by PMA-qPCR. Amplification curves for PMA-treated viable, dead, and a mixture of viable and dead cells of E. coli O157:H7 ATCC 43895 (A) and E. coli MTCC 3221 (B). The Cq values of DNA from viable cells of E. coli O157:H7 ATCC 43895 and E. coli MTCC 3221 has been compared with the $\mathrm{Cq}$ values of dead and mixture of viable and dead cells to indicate that DNA amplification from dead cells is completely inhibited as a result of the PMA-treatment (C). Each bar represents the average $\mathrm{Cq}$ value of a triplicate experiment \pm standard deviation. $\Delta \mathrm{Rn}$, fluorescence intensity change.

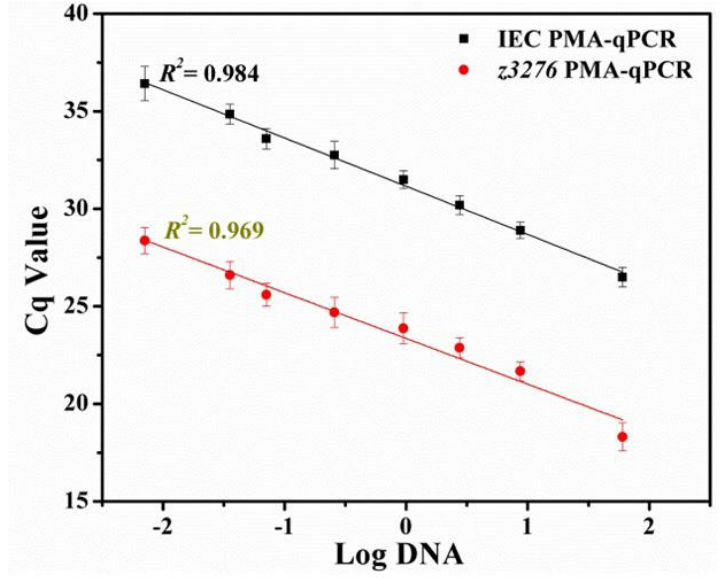

Fig. 2. PMA-qPCR quantification of pure cultures of $E$. coli O157:H7 ATCC 43895 and E. coli MTCC 3221. A series of dilutions of purified DNA (56 pg-0.007pg) extracted from PMA treated viable E. coli cells. The PMA- qPCR could detect as low as $1 \mathrm{CFU} / \mathrm{mL}$ of $E$. coli.
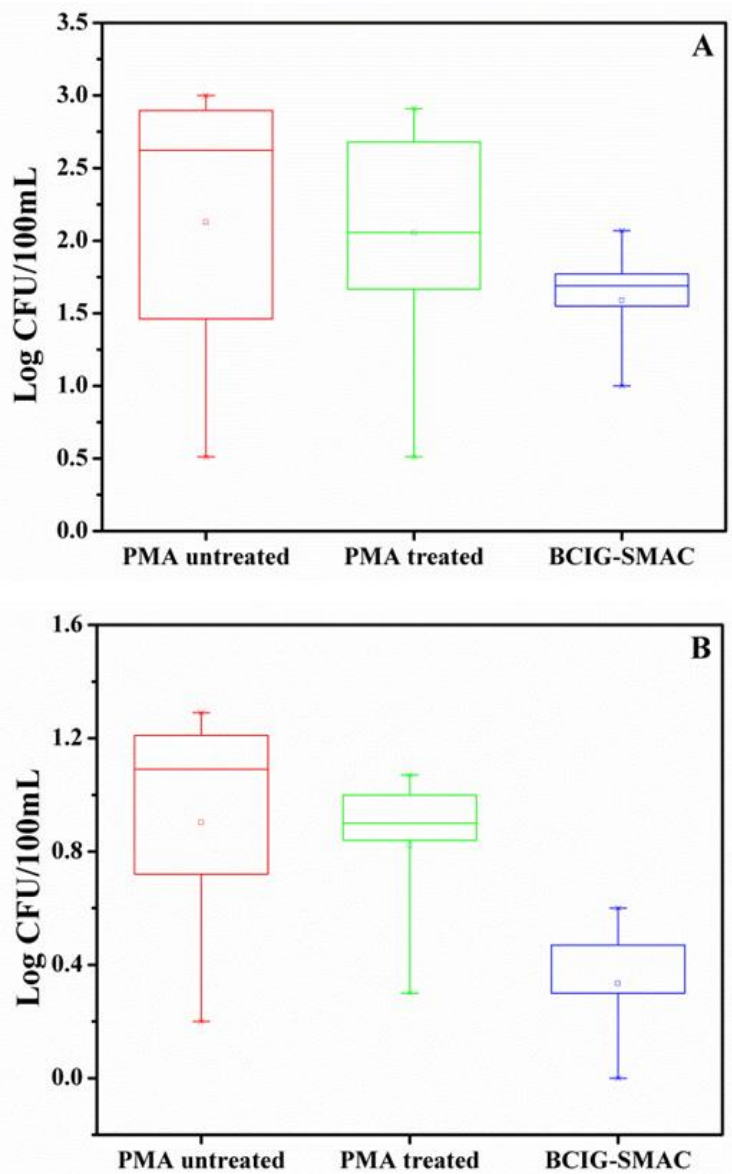

Fig. 3. Box plot for PMA-untreated, PMA-treated qPCR and BCIG-SMAC counts of total viable E. coli (A) and $E$. coli O157:H7 (B) cells from the environmental water samples. Results are reported for $n=71$. 
$1.9 \mathrm{CFU} / 100 \mathrm{~mL}$ to $20 \mathrm{CFU} / 100 \mathrm{~mL}$ (Fig. 3). On the BCIG-SMAC, E. coli O157:H7 cells ranged from $1 \mathrm{CFU} / 100 \mathrm{~mL}$ to $5 \mathrm{CFU} / 100 \mathrm{~mL}$. The total E. coli CFU/100 mL quantified by PMA-qPCR significantly exceeded (paired t-test; $\mathrm{P}<0.05$ ) the number on BCIGSMAC.

\section{DISCUSSION}

Culture-based methods for isolation and identification of $E$. coli are relatively simple and inexpensive; these methods are commonly used in compliance with USEPA water quality standards and guidelines that help monitor the public health. However, one of the significant shortcomings of these culture- based methods is their time consumption (18-96 hours) required for detection and enumeration of $E$. coli with other potential drawbacks such as false-positive and false-negative results, loss of viability of bacteria, and lack of growth of viable but non-culturable bacteria $(17,20)$. Various microbiological media have been developed for isolation and enumeration of waterborne bacteria, such as BCIG-SMAC agar which has been used for differential detection of $E$. coli and E. coli $\mathrm{O} 157: \mathrm{H} 7$.

In the current study, we have evaluated the potentiality of PMA-qPCR for discrimination of viable $E$. coli $\mathrm{O} 157: \mathrm{H} 7$ and E. coli $\mathrm{MTCC} 3221$ strains from dead cells. PMA treatment of viable, dead and mixture of viable and dead cells of E. coli O157:H7 ATCC 43895 and E. coli MTCC 3221 demonstrated that the amplification of DNA from dead cells was almost completely inhibited. Since the Cq values of viable cells and mixed cells are almost identical as indicated in the Fig. 1C, which points out that the amplification of PMA modified DNA from the dead cells in the mixture have hardly taken place. Fold difference of DNA amplification from dead cells was found to be more than three hundred times and one hundred times with respect to mixed viable and dead cells for E. coli $\mathrm{O} 157: \mathrm{H} 7$ and E. coli $\mathrm{MTCC} 3221$ respectively, whereas, negligible fold difference (1.5 and 2.26 for E. coli $\mathrm{O} 157: \mathrm{H} 7$ and E. coli MTCC 3221, respectively) was observed for DNA amplification from viable and mixed viable and dead cells (Fig. 1C). This negligible difference could be due to the trace amount of PMA that entered the viable cells and slightly affected the sensitivity of the PMA-qPCR. Overall, this observation proved that the DNA amplification from dead cells was significantly inhibited in qPCR. Moreover, the PMA-qPCR assay was able to detect as low as $7 \mathrm{fg}$ (approximately equivalent to 1 cell) of DNA of E. coli (Fig. 2). Such a low LOD makes the PMA-qPCR assay significantly useful for assessing the microbiological quality of water samples as bacterial pathogens can cause severe human infections even when present in low numbers such as 10 to 100 cells (the infective dose of $E$. coli O157:H7) (21).

The abundance of $E$. coli strains obtained by PMA-qPCR assay in water samples of Shantinagar area was compared with those estimated using PMA-untreated qPCR and BCIG-SMAC methods. The PMA-treated qPCR analyses revealed values of pathogenic E. coli $\mathrm{O} 157: \mathrm{H} 7$ and total E. coli strain lower than those obtained using PMA-untreated qPCR, which indicated the inhibition of DNA amplification from dead cells. These results demonstrated that PMA-treated qPCR detected more cell numbers of $E$. coli from potable water compared to the BCIGSMAC medium (Fig. 3). These results also indicated that the samples under study contained high numbers of viable but non-culturable $E$. coli cells. The results obtained in our study are in agreement with the earlier reported data in which the application of qPCR yielded abundance of cell number when compared to standard plating method $(5,17,22)$.

Possible anthropogenic factors might have contributed to water contamination such as presence of ill-managed toilets, cattle and lack of sewerage in the area under the study. Anthropogenic parameters majorly affecting water quality in urban areas include industrialization leading to industrial waste discharge, sewage discharge and domestic activities (23, 24). Lenart-Boroń et al. (25) described the effect of anthropogenic factors associated to the municipal sewage inflow and other natural factors such as seasonal variations in water temperature therein affecting the number of some bacterial groups (25). Humans, livestock and domestic animals are deemed as natural sources of faecal contamination and especially human faecal wastes have been reported behind the risk of waterborne diseases. In the present study, possible anthropogenic factors that might have contributed to water contamination are sewage discharge or lack of proper sewerage in the area and domestic cattle in case of water samples collected from the wells and households 1 and 3 (Supplementary Table S1). Our results showed that special attention must be given in low income rural areas, where water quality assess- 
ment data are hardly available, and more extensive studies should be performed. The study outlined here can pave the way for better attention towards the provision of safe potable water in the country.

\section{CONCLUSION}

The significance of sufficient quality of water for public health cannot be underestimated. The values of total viable $E$. coli and $E$. coli $\mathrm{O} 157: \mathrm{H} 7$ indicated the deteriorating condition of water in the area which might threaten the inhabitants at increased risks of acquiring diseases caused by pathogenic bacteria. The results fall outside the regulatory limits of water quality assessment probably indicating that the water in this area might not be safe and therefore needs special attention for proper treatments of water for human consumption.

\section{ACKNOWLEDGEMENTS}

Authors sincerely thank the CORE-WWEM grant of BITS Pilani. The first author sincerely thanks the Indian Council of Medical Research, New Delhi, India for the senior research fellowship award.

\section{REFERENCES}

1. UNICEF Somalia - Water, Sanitation and Hygiene Priority issues. Retrieved August 2019. https://www.unicef.org/somalia/water-sanitation-andhygiene

2. Ramírez-Castillo FY, Loera-Muro A, Jacques M, Garneau P, Avelar-González FJ, Harel J, et al. Waterborne pathogens: detection methods and challenges. Pathogens 2015; 4: 307-334.

3. Deshmukh RA, Joshi K, Bhand S, Roy U. Recent developments in detection and enumeration of waterborne bacteria: a retrospective minireview. MicrobiologyOpen 2016; 5: 901-922.

4. March SB, Ratnam S. Sorbitol-MacConkey medium for detection of Escherichia coli O157:H7 associated with hemorrhagic colitis. J Clin Microbiol 1986; 23: 869872.

5. Deshmukh RA, Bhand S, Roy U. A novel molecular quantitative method for rapid and sensitive detection of Escherichia coli from roof-harvested rainwater. Anal Methods 2019; 11: 3155-3167.

6. Maheux AF, Bissonnette L, Boissinot M, Bernier JL,
Huppé V, Picard FJ, et al. Rapid concentration and molecular enrichment approach for sensitive detection of Escherichia coli and Shigella species in potable water samples. Appl Environ Microbiol 2011; 77: 61996207.

7. Wang S, Levin RE. Discrimination of viable Vibrio vulnificus cells from dead cells in real-time PCR. $J$ Microbiol Methods 2006; 64: 1-8.

8. Oliver DM, Bird C, Burd E, Wyman M. Quantitative PCR profiling of Escherichia coli in livestock feces reveals increased population resilience relative to culturable counts under temperature extremes. Environ Sci Technol 2016; 50: 9497-9505.

9. Li B, Liu H, Wang W. Multiplex real-time PCR assay for detection of Escherichia coli $\mathrm{O} 157: \mathrm{H} 7$ and screening for non-O157 Shiga toxin-producing E. coli. BMC Microbiol 2017; 17: 215.

10. Nocker A, Camper AK. Selective removal of DNA from dead cells of mixed bacterial communities by use of ethidium monoazide. Appl Environ Microbiol 2006; 72: 1997-2004.

11. Alvarez G, González M, Isabal S, Blanc V, León R. Method to quantify live and dead cells in multi-species oral biofilm by real-time PCR with propidium monoazide. AMB Express 2013; 3: 1.

12. Elizaquível P, Sánchez G, Selma MV, Aznar R. Application of propidium monoazide- qPCR to evaluate the ultrasonic inactivation of Escherichia coli $\mathrm{O} 157: \mathrm{H} 7$ in fresh-cut vegetable wash water. Food Microbiol 2012; 30: 316-320.

13. Hellein KN, Kennedy EM, Harwood VJ, Gordon KV, Wang SY, Lepo JE. A filter-based propidium monoazide technique to distinguish live from membrane-compromised microorganisms using quantitative PCR. J Microbiol Methods 2012; 89: 76-78.

14. Nocker A, Cheung CY, Camper AK. Comparison of propidium monoazide with ethidium monoazide for differentiation of live vs. dead bacteria by selective removal of DNA from dead cells. J Microbiol Methods 2006; 67: 310-320.

15. Taskin B, Gozen AG, Duran M. Selective quantification of viable Escherichia coli bacteria in biosolids by quantitative PCR with propidium monoazide modification. Appl Environ Microbiol 2011; 77: 4329-4335.

16. Nocker A, Sossa-Fernandez P, Burr MD, Camper AK. Use of propidium monoazide for live/dead distinction in microbial ecology. Appl Environ Microbiol 2007; 73: 5111-5117.

17. Li B, Chen JQ. Real-time PCR methodology for selective detection of viable Escherichia coli $\mathrm{O} 157$ : $\mathrm{H} 7$ cells by targeting Z3276 as a genetic marker. Appl Environ Microbiol 2012; 78: 5297-5304.

18. Khan IU, Gannon V, Kent R, Koning W, Lapen DR, Miller J, et al. Development of a rapid quantitative 
PCR assay for direct detection and quantification of culturable and non-culturable Escherichia coli from agriculture watersheds. J Microbiol Methods 2007; 69: 480-488.

19. Picard FJ, Gagnon M, Bernier MR, Parham NJ, Bastien $\mathrm{M}$, Boissinot $\mathrm{M}$, et al. Internal control for nucleic acid testing based on the use of purified Bacillus atrophaeus subsp. globigii spores. J Clin Microbiol 2009; 47: 751-757.

20. Walker DI, McQuillan J, Taiwo M, Parks R, Stenton $\mathrm{CA}$, Morgan H, et al. A highly specific Escherichia coli qPCR and its comparison with existing methods for environmental waters. Water Res 2017; 126: 101-110.

21. Ibekwe AM, Grieve CM. Detection and quantification of Escherichia coli O157:H7 in environmental samples by real-time PCR. J Appl Microbiol 2003; 94: 421-431.
22. Luna GM, Dell'Anno A, Pietrangeli B, Danovaro R. A new molecular approach based on qPCR for the quantification of fecal bacteria in contaminated marine sediments. J Biotechnol 2012; 157: 446-453.

23. Edberg SC, Rice EW, Karlin RJ, Allen MJ. Escherichia coli: the best biological drinking water indicator for public health protection. Symp Ser Soc Appl Microbiol 2000; (29): 106S-116S.

24. Khatri N, Tyagi S. Influences of natural and anthropogenic factors on surface and groundwater quality in rural and urban areas. Front Life Sci 2015; 8: 23-39.

25. Lenart-Boroń A, Wolanin A, Jelonkiewicz E, Żelazny $M$. The effect of anthropogenic pressure shown by microbiological and chemical water quality indicators on the main rivers of Podhale, Southern Poland. Environ Sci Pollut Res Int 2017; 24: 12938-12948. 